CORRIGENDUM

doi:10.1038/nature12078

\title{
Corrigendum: Mitochondrial Atpifl regulates haem synthesis in developing erythroblasts
}

Dhvanit I. Shah, Naoko Takahashi-Makise, Jeffrey D. Cooney, Liangtao Li, Iman J. Schultz, Eric L. Pierce, Anupama Narla, Alexandra Seguin, Shilpa M. Hattangadi, Amy E. Medlock, Nathaniel B. Langer, Tamara A. Dailey, Slater N. Hurst, Danilo Faccenda, Jessica M. Wiwczar, Spencer K. Heggers, Guillaume Vogin, Wen Chen, Caiyong Chen, Dean R. Campagna, Carlo Brugnara, Yi Zhou, Benjamin L. Ebert, Nika N. Danial, Mark D. Fleming, Diane M. Ward, Michelangelo Campanella, Harry A. Dailey, Jerry Kaplan \& Barry H. Paw

Nature 491, 608-612 (2012); doi:10.1038/nature11536

On page 610 of this Letter, the overview comments concerning the action of ATP synthase should read: "Under physiological conditions, the $\mathrm{F}_{1} \mathrm{~F}_{0}$-ATP synthase generates ATP by consuming the proton motive force existing across the inner mitochondrial membrane, transporting $\mathrm{H}^{+}$ions from the intermembrane space into the mitochondrial matrix $^{8,15}$. When respiration is inhibited or the mitochondrial membrane potential $(\Delta \Psi \mathrm{m})$ is decreased, the $\mathrm{F}_{1} \mathrm{~F}_{0}$-ATP synthase reverses the direction of $\mathrm{H}^{+}$transport, dissipating ATP in the attempt to maintain the proton motive force ${ }^{8,15}$. Under these conditions, Atpif1 inhibits the reversal of the $\mathrm{F}_{1} \mathrm{~F}_{0}$-ATP synthase to decrease ATP hydrolysis, thereby counteracting the maintenance of the mitochondrial membrane potential $(\Delta \Psi \mathrm{m})$ and proton motive force ${ }^{8 "}$. This rewording has no effect on the data, the scientific interpretation and the resulting model presented, and has been corrected in the HTML and PDF versions of the original paper. 